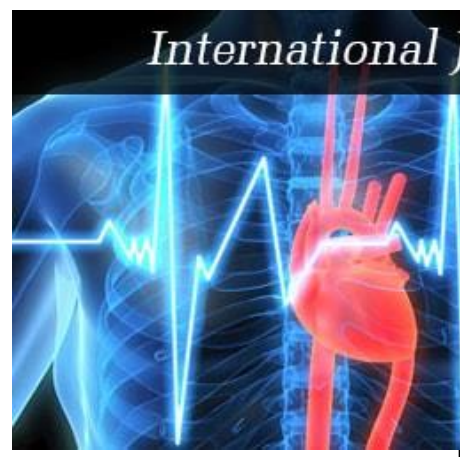

ISSN: $2456-0057$

IJPNPE 2020; 5(2): 29-31

(C) 2020 IJPNPE

www.journalofsports.com

Received: 20-05-2020

Accepted: 22-06-2020

Dr. Mohammed Shosha

Department of Special Therapy,

Kitzberg Clinic, Bad

Mergentheim, Germany
Corresponding Author: Dr. Mohammed Shosha Department of Special Therapy, Kitzberg Clinic, Bad

Mergentheim, Germany

\section{A brief introduction to therapeutic boxing}

\section{Dr. Mohammed Shosha}

DOI: https://doi.org/10.22271/journalofsport.2020.v5.i2a.1977

\section{Abstract}

Therapeutic boxing exercise offers a unique and fun approach to the prevention and treatment of various physical and mental health problems. The purpose of the present paper was to review and analyze the existing data about boxing in the therapy and its role in enhancing physical and mental health for people at different ages and with various types of diseases. Potentially related data were narratively retrieved from PubMed, Google and Google Books. The keywords included the terms "Boxing", "Therapy" and "Therapeutic boxing". This search aimed to discover the world of therapeutic boxing and to introduce it as one of the modern therapy methods which can be used to treat and prevent several mental and physical health problems. Further future experimental studies still needed.

Keywords: Sport; health; exercise; rehabilitation; therapy

\section{Introduction}

Physical activity is one of the most important things which everyone can do for health. Physical activity and exercise can have immediate and long-term health benefits, being active can reduce the risk of developing several diseases, improve health conditions and maintain a state of well-being.

Boxing training includes different kinds of activity. All these activities improve general fitness, strength, speed, agility, hand-eye coordination and endurance.

This educational search paper thus examines the results of related data concerning the possible impact and effectiveness of "Therapeutic Boxing" on health conditions for people of different ages.

\section{Materials and methods}

To obtain the desired data for this educational paper, the electronic sources PubMed, Google and Google books were searched. Those websites were searched for evidence of the successful implementation of therapeutic boxing.

\section{Search results}

After reviewing the related found data, some useful data were extracted and checked. Search results are reported/described below:

\subsection{The role of physical activity and exercises in the rehabilitation}

The aim of the rehabilitation is to restore function to the greatest degree in the shortest time, helping people return to their function with minimal risk of re-injury. Exercise is generally considered to be a safe and efficacious approach to restoring function in patients with various diseases (Porter, 2015) ${ }^{[11]}$.

Many studies show that exercise benefits physical and mental health, both of which are important in the recovery process following many injuries or diseases. Physical activity and exercise can effectively help with rehabilitation and recovery.

\subsection{Physical activity in the therapy}

Therapy is the core of any successful Rehabilitation program. It concerned with restoring and compensating for the loss of functioning, and preventing or slowing deterioration in functioning in every area of a person's life (WHO, 2011) ${ }^{[12]}$. 
There are multiple physical activities and exercise that appear in the therapy programs such as: Ballet therapy, Cycling therapy, Boxing therapy, Dance therapy, Climbing therapy, Biking therapy, Running therapy, Swimming therapy and more (Francis A. Martin, 2020, Francis\& Turner, 2020) ${ }^{[3,4]}$.

\subsection{Boxing in the therapy}

For centuries, boxing has been an integral part of civilized and uncivilized societies and has undergone several transitions reflective of the times (Jordan, 1993) ${ }^{[7]}$.

Using Boxing as a form of physical activity and as a part of the therapy for people with different diseases can have many positive health effects (Long \& Robertson, 2020) ${ }^{[8]}$.

\subsection{The physical and mental health benefits of therapeutic boxing}

According to the existing data, boxing offers a possibility to deal physically with the topic of rage (and other emotions), to reduce inner tension and to improve body perception and the ability for social interaction.

Therapeutic boxing can have a positive impact on the speech, social interaction Skills, and mental health of individuals with Parkinson's disease (Meinert \& Hatkevich, 2019) ${ }^{[10]}$.

Boxing as a therapy form has many positive effects, specifically for older adults with different diseases. Benefits of boxing include improved gait, balance, activities of daily living and quality of life (Long \& Robertson, 2020) ${ }^{[8]}$.

Therapeutic boxing helps young people and children with a mental health problem (Bisp, 2018) ${ }^{[2]}$.

Physical activity and movement rehabilitation are most beneficial for each individual across the different stages of some diseases progression, boxing could be most beneficial in the early to middle stages of the progression (Meg E et al., 2019) ${ }^{[9]}$.

Therapeutic boxing exercise considered one of the effective rehabilitation programs for COPD patients in stable phases in communities (Gu et al., 2012) ${ }^{[5]}$.

Boxing improves balance, strengthens upper- body and core, boosts endurance, may increase alertness, Enhances mood, helps posture, improves hand-eye coordination, and it's a Great way to fight mental illnesses (Harvard University, 2015) ${ }^{[6]}$.

Not only that, but boxing as therapy can help with stress and anger management, Boosts confidence and self-esteem, elevate mood and serve as a form of natural anti-anxiety, improves focus and Improves sleep quality.

\section{Discussion}

Physical activity and exercise is an essential part of most of rehabilitation and prevention programs, whether mentally, psychology or physically and it could be very important to build a good lifestyle and health conditions ${ }^{[1,3,4,9,12]}$.

According to scientific literature, boxing (therapeutic boxing) considered as one of the useful therapy methods for people with various mental and physical health problems $[3,4,5,6,7,8,9$, 10].

It could be interesting to include therapeutic boxing to other therapy methods for both children and adults with unstable health conditions especially mental and psychological ones.

\section{Conclusion}

In conclusion, there is a large amount of significant data which shows that therapeutic boxing can have a significant positive effect on the rehabilitation and recovery from a wide range of diseases, as well as being beneficial to physical, psychological and mental health.

More future experimental studies still needed to provide a better understanding of the impact of therapeutic boxing on people with some mental and physical diseases. Its role in the prevention of mental problems might be addressed in the future researches.

\section{Authorship}

A Brief Introduction to Therapeutic Boxing was developed by Dr. Mohammed Shosha (e-mail address: dr.modyshosha @yahoo.com).

\section{Disclaimer}

This information is not meant to replace the advice of a medical professional and should not be interpreted as a clinical practice guideline. This Information/Education Paper may be reproduced for noncommercial use for health care professionals and other service providers to share with their patients or clients. Any other reproduction is subject to approval by the publisher.

\section{Conflict of interest}

None.

\section{Source of funding}

None.

\section{References}

1. Bär KJ, Markser VZ. Sport Specificity of Mental disorders: the issue of sport psychiatry. European archives of psychiatry and clinical neuroscience. 2013; 263:205-210.

2. Bisp M. Non- contact boxing therapy breeding optimism in Bristol's young. Mental health today. [Online]. Available,

2018: https://www.mentalhealthtoday.co.uk/blog/youngpeople/non-contact-boxing-therapy-breeding-optimismin-bristols-young

3. Francis AM. Therapy Thieves- How to save Mental Health Care from Its Providers. Oxford university press, New York, USA, 2020.

4. Francis AM, Turner J. Clinical Supervision in the Real world: A practical Guide to Ethics, legal Issus, and Personal Development. Rutledge Publication. New York, USA, 2020.

5. Gu G, Zhou YM, Wang DL, Chen L, Zhong NS, Ran PX. Effects of Shadow Boxing Training on Exercise Endurance and quality of life of Patients with Chronic Obstructive Pulmonary disease. Nat Med J China. [Online]. 2012; 92(14):952-955. Availabe: http://rs.yiigle.com/CN112137201214/123735.htm

6. Harvard Health Letter. Punch up your exercise routine with fitness boxing: the adapted version of the sport can help improve your strength, endurance, and balance. Harvard Medical School. Harvard Health Publication. [Online]. Available, 2015: https://www.health.harvard.edu/exercise-andfitness/punch-up-your-exercise-routine-with-fitnessboxing

7. Jordan B. Medical Aspects of Boxing. Library of Cataloging in Publication Data. USA, 1993.

8. Long T, Robertson T. Foundation of Therapeutic Recreation. Human Kinetics. USA, 2020.

9. Meg EM, Terry E, Dana J, Hazel H, Andrea T, Arun T, Susan S. Boxing for Parkinson's disease: Has 
Implementation Accelerated Beyond Current Evidence?. Frontiers in Neurology. [Online]. Available, 2019: https://www.frontiersin.org/articles/10.3389/fneur.2019.0 1222/full

10. Meinert R, Hatkevich B. The Effects of Community Based therapeutic Boxing on the speech, social interaction skills, and mental health of individuals with parkinson's disease, The Journal of occupational Therapy. 2019; 73:1.

11. Porter C, Hardee J, Herndon D, Suman O. The role of Exercise in the Rehabilitation of Patients with several Burns. Exercise and sport sciences Reviews. [Online]. 43(1). Pp.34-40. Available, 2015:

https://journals.lww.com/acsmessr/Fulltext/2015/01000/The_Role_of_Exercise_in_the_ Rehabilitation_of.7.aspx

12. World Health Organization (WHO). Disabilities world report- Chapter 4: Rehabilitation. [Online]. Pp.1. Available, 2011: https://www.who.int/disabilities/world_report/2011/chapt er4.pdf 